\title{
Bending performance of concrete beams strengthened with textile reinforced mortar TRM
}

\author{
Lluís Gil ${ }^{1, a}$, Christian Escrig ${ }^{1, b}$ and Ernest Bernat ${ }^{1, c}$ \\ ${ }^{1}$ Department of Strength of Materials and Structures in Engineering \\ Universitat Politècnica de Catalunya UPC. BarcelonaTech \\ ETSEIAT, c/ Colom 11, 08022, Terrassa, Spain \\ alluis.gil@upc.edu, ${ }^{b}$ christian.escrig@upc.edu, cernest.bernat@upc.edu
}

Keywords: TRM, concrete, strengthening.

\begin{abstract}
This work presents a method of strengthening concrete structures based on textiles of high strength and mortars. The combination of textiles and mortars produces a new composite material with cementitious matrix. This material can be used for the reinforcement of concrete beams under bending loads. We tested several combinations of fibers: glass, Poliparafenil Benzobisoxazol (PBO), steel and carbon fibers with mortar and we used them to reinforce precast concrete beams. All the specimens were tested with a four-point load test. We discuss the performance of the specimens and we compare the ultimate results with the formulae from FRP codes.
\end{abstract}

\section{Introduction}

The reinforcement of concrete structures is a worldwide problem. Durability and corrosion play an important role in the loss of strength of concrete beams. Nowadays, maintenance programs repair periodically the most relevant infrastructures. From the 60's a good reinforcement strategy is the use of Fiber Reinforced Polymers FRP [1]. This technology uses different types of fibers, commonly carbon or aramid fibers, mixed with organic resin that creates a layer of composite material. Another possibility is to attach composite laminates with the use of epoxy resin. Both technologies are based on organic matrices that have some drawbacks: volatile elements that affect the safety of workers, low fire resistance and unknown performance at a long time [2].

Lately the use of inorganic matrices for manufacturing such composite solutions opened a new paradigm in the reinforcement strategy of concrete. The mix of different types of fibers and cementitious matrices creates composite materials with good strength performance. These new materials are called Textile Reinforced Mortars (TRM) because fibers are manufactured in the form of fabric and the inorganic matrix is always a mortar with a high percentage of cement and a low content of fine aggregates. Other authors have developed basic studies about this new material (see [3,4]).

In this study precast concrete beams have been reinforced with different types of fibers. We wanted to know if there is any difference in the performance of the composite materials and their availability as reinforcement against bending. The possibility of reinforcing with different material stiffness could provide customized solutions for a wide variety of structures suffering aging, corrosion or simply strengthening for re-use. Moreover, the use of this new technology could overcome the sustainability and fire problems that traditional organic FRP solutions present.

\section{Experimental programme}

Test specimens and materials. For this experimental study, ten precast commercial beams of small size were reinforced with different strategies. The materials used to cast the beams were concrete $\left(f_{c}=43 \mathrm{MPa}\right)$ and steel prestressed reinforcement $\left(f_{p}=1164 M P a\right)$. Five different types of fibers (Table 1$)$ were combined with four different types of mortars (Table 2) to obtain five different types of strengthened beams, with two repetitions in every case. Equivalent thickness of each textile (based on the equivalent smeared distribution of fibers) is included in Table 1. The designation of each specimen is obtained joining both designations (fibers and mortars). Also, a control beam without any reinforce was tested.

The reinforcement was applied on the weakest bending position [Fig. 1] in order to ensure the specimen collapse with the designed procedure test. The details of application of the Textile Reinforced Mortar (TRM) 
to concrete beams have been described by Brückner et al. [5] and Larrinaga et al. [6]. Reinforced beams were air cured at room temperature for more than 28 days.

Table 1. Fibers materials and mechanical properties

\begin{tabular}{cccccc}
\hline Material & $\begin{array}{c}\text { Tensile } \\
\text { Strength } \\
\boldsymbol{f}_{\boldsymbol{f k}}(\mathbf{M P a})\end{array}$ & Failure Strain & $\begin{array}{c}\text { Young's } \\
\text { Modulus } \\
\boldsymbol{E}_{f u}(\mathbf{G P a})\end{array}$ & $\begin{array}{c}\text { Equivalent } \\
\text { Thickness } \\
\boldsymbol{t}_{\boldsymbol{f}}(\boldsymbol{m m})\end{array}$ & Designation \\
\hline Glass & 2600 & $\boldsymbol{\varepsilon}_{\boldsymbol{f u}}(\boldsymbol{\%})$ & 90 & 0,0042 & $\mathrm{~V}$ \\
\hline PBO & 5800 & 2,15 & 270 & 0,0455 & $\mathrm{P}$ \\
\hline LD-Steel & 3070 & 1,60 & 190 & 0,0750 & $\mathrm{~A} 4$ \\
\hline HD-Steel & 3070 & 1,60 & 190 & 0,2270 & $\mathrm{C} 12$ \\
\hline Carbon & 3400 & 1,80 & 240 & 0,0470 & $\mathrm{C}$ \\
\hline
\end{tabular}

Table 2. Mechanical properties of the mortars

\begin{tabular}{cccc}
\hline Type of Mortar & $\begin{array}{c}\text { Compressive Strength } \\
(\mathbf{M P a})\end{array}$ & $\begin{array}{c}\text { Flexural Strength } \\
(\mathbf{M P a})\end{array}$ & Designation \\
\hline Bicomponent mortar with high strength cement & 34,84 & 8,63 & PHDM \\
\hline Hydraulic mortar with fibers and additives & 30,02 & 10,65 & XM750 \\
\hline Hydraulic puzzolanic mortar & 24,70 & 7,87 & XM25 \\
\hline Hydraulic mortar with polymeric additives (PCC) & 24,46 & 8,13 & $\mathrm{R} 3$ \\
\hline
\end{tabular}
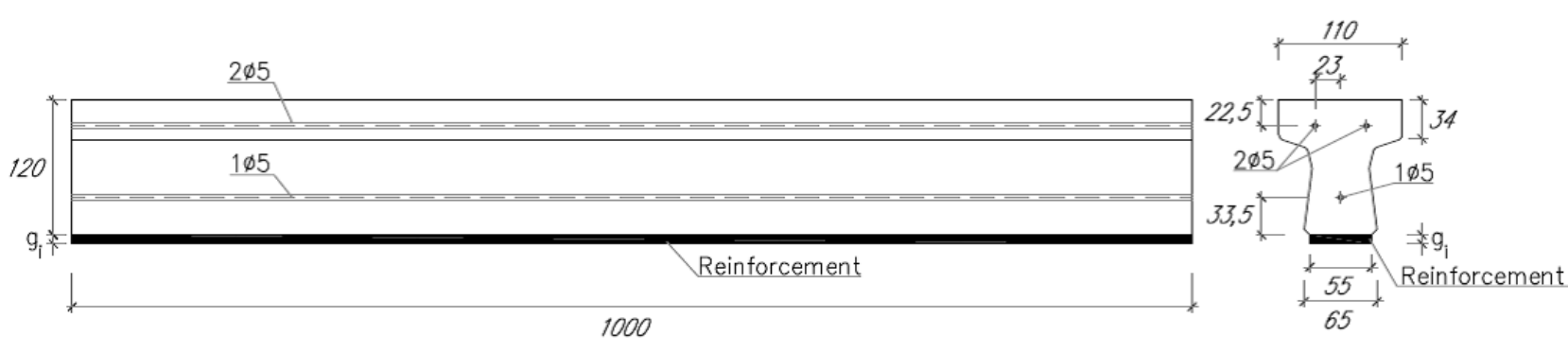

Figure 1. Lateral view and cross-section view of the strengthened specimen (units in mm)

Testing procedure. Specimens were subjected to four-points bending tests. They were supported on two cylindrical steel rods which defined a free span of $900 \mathrm{~mm}$ and then aligned with the line of actions of the load. The load was applied using a distribution steel beam fixed to the mobile part of an electromechanical press (force range $50 \mathrm{kN}$ ). Two potentiometers were placed below the specimen and set to measure the deflection at mid-span. Values were averaged later on data process. Force and displacement of each potentiometer were simultaneously recorded at $50 \mathrm{~Hz}$. The load application was displacement-controlled at a fixed ratio of $1 \mathrm{~mm} / \mathrm{min}$. Once the maximum load was reached and the load-bearing capacity of the specimen fell below a certain limit $(1 \mathrm{kN})$, the test was stopped. Finally, the real TRM thickness was measured on the broken cross-section. The test setup is presented in Figure 2.
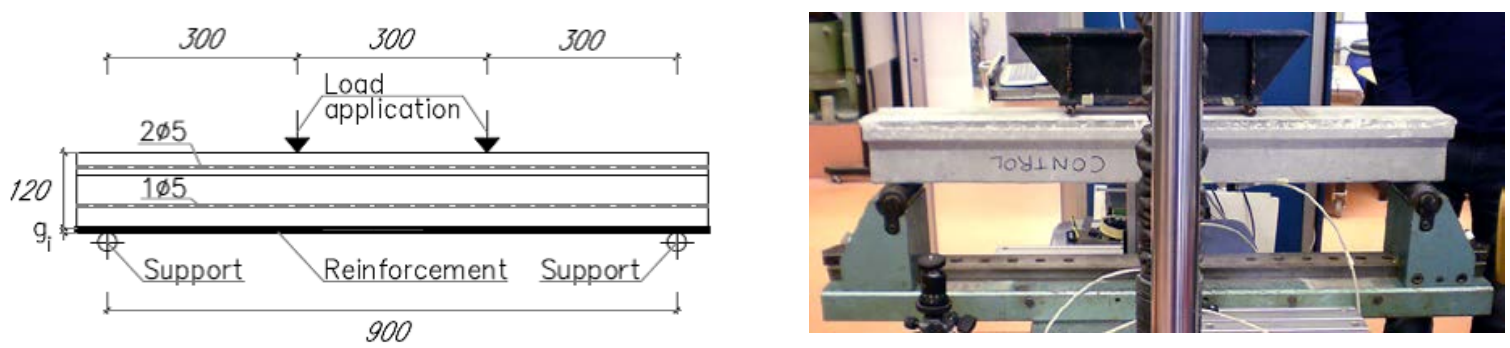

Figure 2. Test set-up (units in mm)

\section{Results and discussion}

Test results. Table 3 summarizes the results of the experimental campaign. This table includes the maximum bending moment at mid-span $\left(\mathrm{M}_{\mathrm{u}}\right)$, the deflection at mid-span $\left(\delta_{\mathrm{u}}\right)$ for the maximum loading state, the TRM thickness $\left(\mathrm{g}_{\mathrm{i}}\right)$ and the failure mode. Three different failure modes (Figure 3) were noticed in the presented experimental campaign: 
a) Flexure failure. Fibers broke when their maximum allowable elongation was reached.

b) Shear failure. Flexural cracks did not appear in the beam. Shear crack crossed along the section when the shear capacity of the beam was reached.

c) Debonding failure. TRM reinforcement debonds.

Table 3. Summary of test results

\begin{tabular}{ccccc}
\hline Designation & $\boldsymbol{M}_{\boldsymbol{u}}(\boldsymbol{k} \boldsymbol{N} \cdot \boldsymbol{m})$ & $\boldsymbol{\delta}_{\boldsymbol{u}}(\mathbf{m m})$ & $\boldsymbol{g}_{\boldsymbol{i}}(\mathbf{m m})$ & Failure mode \\
\hline CONTROL & 1,92 & 9,83 & - & Flexure \\
\hline VPHDM-01 & 2,20 & 9,58 & 4 & Flexure \\
\hline VPHDM-02 & 3,36 & 14,31 & 7 & Flexure \\
\hline PXM750-01 & 3,04 & 13,11 & 8 & Flexure \\
\hline PXM750-02 & 3,76 & 11,61 & 10 & Flexure \\
\hline A4R3-01 & 3,31 & 10,97 & 7 & Shear \\
\hline A4R3-02 & 3,95 & 12,44 & 7 & Shear \\
\hline A12R3-01 & 2,78 & 4,24 & 6 & Debonding \\
\hline A12R3-02 & 3,56 & 14,83 & 11 & Debonding \\
\hline CXM25-01 & 2,16 & 8,27 & 8 & Flexure \\
\hline CXM25-02 & 2,42 & 8,36 & 10 & Flexure \\
\hline
\end{tabular}

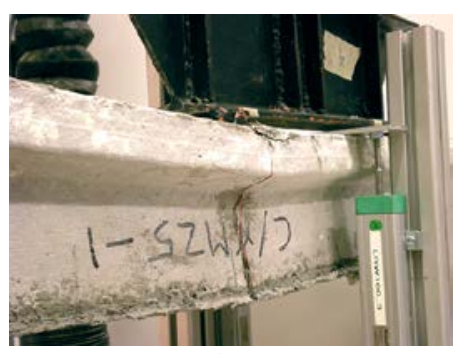

a) Flexure

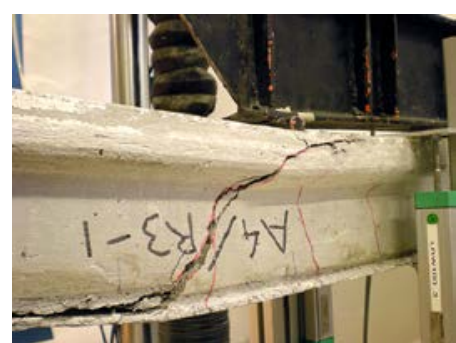

b) Shear

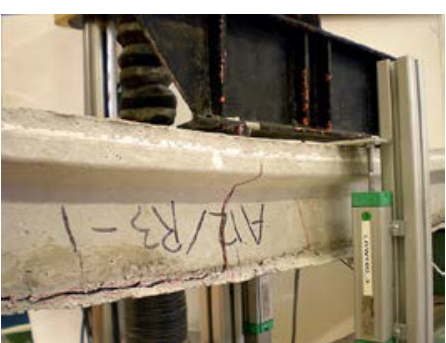

c) Debonding

Figure 3. Failure modes of the specimens tested

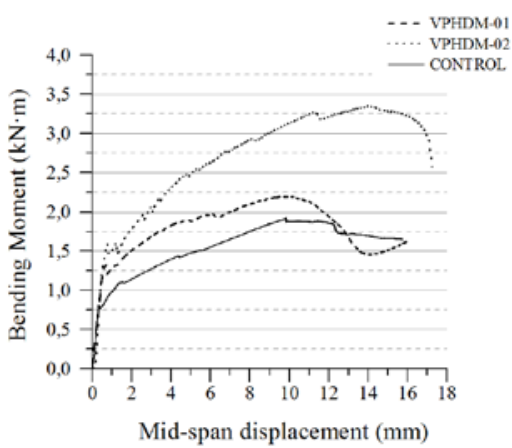

a) Glass vs control

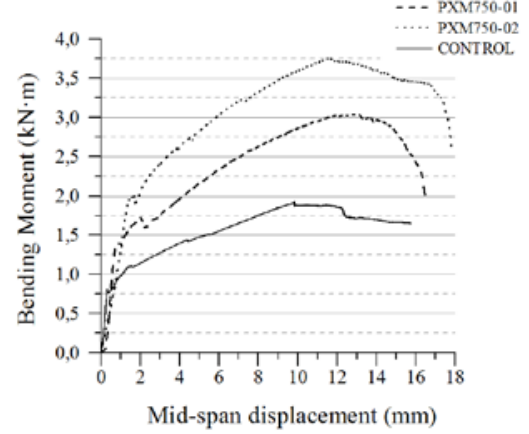

b) PBO vs control

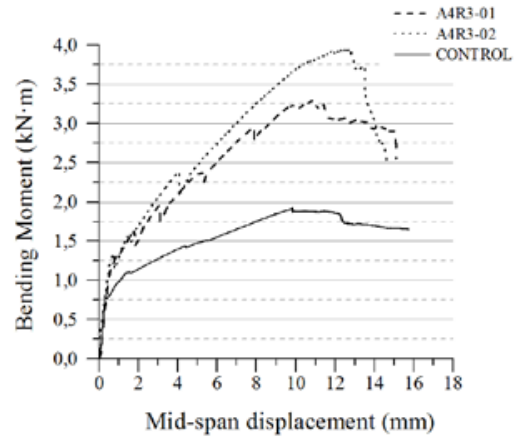

c) Low density steel vs control

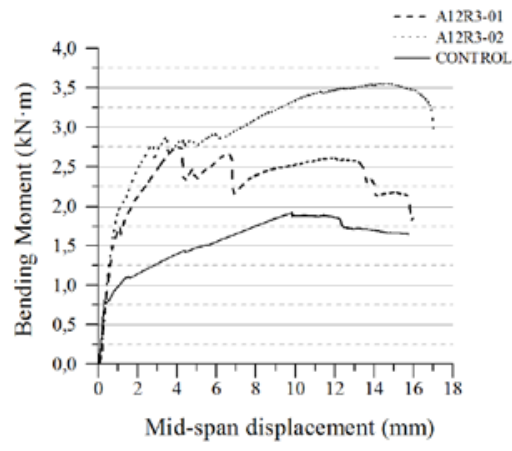

d) High density steel vs control

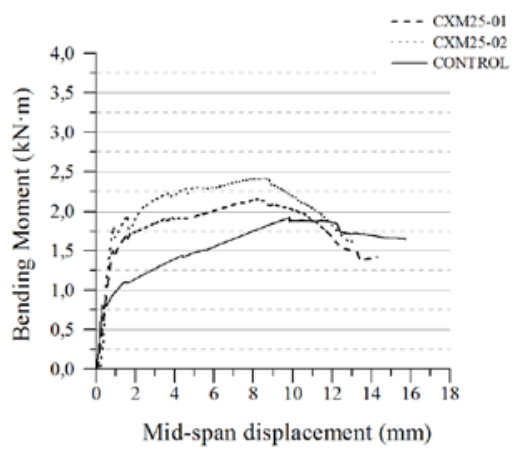

e) Carbon vs control

Figure 4. Graphs of load versus mid-span displacement of tested beams 
Figure 4 shows the mechanical response of the strengthened specimens related with the control beam behaviour. The relationship between the applied bending moment and mid-span displacement is presented for each case.

Discussion. Most of reinforcements did not show debonding failure. The adhesive performance between the inorganic matrix and the concrete surface mostly worked, except for samples A12R3-01 and A12R3-02. In both cases the fabric was too dense and the mortar could not penetrate enough between the rovings. This is an important limitation of the technology for dense grids. Samples of steel fabrics A4R3-01 and A4R3-02 improved the bending capacity until a level that produced failure by shear instead of bending. Other reinforced specimens increased load bearing capacity and showed flexural failure. PBO strengthened beams performed the best while carbon strengthened ones were the worst. In the case of carbon reinforcement chemical incompatibility with mortar could produce the loss of strength. Nevertheless, manufacturing errors could also be responsible. Finally, glass fibers showed a little inhomogeneous performance.

The classical equilibrium at the cross-section is used to calculate the failure according the FRP code [7]. Equilibrium of forces and compatibility of strains produce equations at the collapse. In the case of PBO, failure produces by concrete crushing. Hence the compatibility equation is $\varepsilon_{\mathrm{c}}=\varepsilon_{\mathrm{cu}}$ being, $\varepsilon_{\mathrm{c}}$ the deformation of concrete and $\varepsilon_{\mathrm{cu}}$ the ultimate concrete deformation: 0,0035 . While the glass fiber reinforcement produced the stress yielding of TRM, the compatibility equation stands for $\varepsilon_{\mathrm{f}}=\varepsilon_{\mathrm{fu}}$ being $\varepsilon_{\mathrm{f}}$ the deformation of TRM and $\varepsilon_{\mathrm{fu}}$ the ultimate deformation of glass fibers: 0,03. Carbon did not contribute significantly to the strength mechanism and the failure occurred by yielding of prestressed steel, like the control beam.

\section{Conclusions}

TRM is a new technology of composite material based in a cementitious matrix. Different types of fibers and mortars have been used to manufacture reinforcement for strengthening of prestressed beams. The reinforcement was tested in a four-point bending test. Most of the composite reinforcements were not debonded but a single one (HD-Steel). Low density steel fibers showed the most efficient performance increasing the bending capacity and producing a collapse by the shear of the specimen. PBO was the fiber that increased the bending strength. The failure happened at the concrete head. Carbon and glass fibers presented the worst results despite of increasing load bearing capacity. Manufacture and chemical compatibility seem to be important issues for a proper strength performance.

\section{References}

[1] C. E. Bakis, L. C. Bank, V. L. Brown, E. Cosenza, J. F. Davalos, J. J. Lesko, A. Machida, S. H. Rizkalla, and T. C. Triantafillou, Fiber-Reinforced Polymer Composites for Construction-State-ofthe-Art Review, Journal of Composites for Construction, vol. 6, no. 2 (2002), 73-87.

[2] D. Bournas and P. Lontou, Textile-reinforced mortar versus fiber-reinforced polymer confinement in reinforced concrete columns, ACI Structural Journal, no. 104-S70 (2007), 740-748.

[3] T. C. Triantafillou and C. G. Papanicolaou, Shear strengthening of reinforced concrete members with textile reinforced mortar ( TRM ) jackets, Materials and Structures, vol. 39, no. 8 (2006), 93-103.

[4] E. Bernat, L. Gil, P. Roca, and C. Escrig, Experimental and analytical study of TRM strengthened brickwork walls under eccentric compressive loading, Construction and Building Materials, vol. 44 (2013), 35-47.

[5] A. Brückner, R. Ortlepp, and M. Curbach, Textile reinforced concrete for strengthening in bending and shear, Materials and Structures, vol. 39, no. 8 (2006), 741-748.

[6] P. Larrinaga, D. García, L. Garmendia, and J. Díez, Experimental study of the flexural behaviour of low performance RC beams strengthened with textile reinforced mortar, in International Conference on Material Science and 64th RILEM Annual Week in Aachen - MATSCI 1 (2010), 1-10.

[7] CEP-FIP fib Bulletin 14. Externally bonded FRP reinforcement for RC structures. 2001. 